\title{
Michel Serres, die ondeunde denker - 'n huldeblyk
}

Die dood van Michel Serres op 1 Junie 2019 was hartseer, soos die dood meesal is. Tog is daar ryk en kosbare vertroosting in sy nalatenskap. Hy het die geheim geken om ondanks omstandighede altyd vreugdevol en selfs vredevol te lewe, met 'n tikkie speelsheid, selfs guitigheid, wat alles in sy omvangryke oeuvre weerspieël word en raakgelees kan word. Die erns van die meeste filosowe was vir hom een te veel.

"Yster slyp yster, so slyp een mens die persoon van die ander" ( Spreuke 27:17). Hierdie slypwerk geskied deur persoonlike verkeer, deur gesprekvoering en taal, en deur leeswerk. Boeke transformeer, gee rigting, vorm, dring die gees binne en keer dit dikwels om. Boeke bring ons nader aan ander, lei ons in hulle siele, gees en denke in. Sy dood het my die afgelope jaar weer met vertroosting, maar ook met 'n sublieme verlustiging na sy ryk nalatenskap van meer as 70 boeke oor ' $n$ halwe eeu laat gryp. Om dit weer te fynkam was intellektueel besonder verfrissend.

Die, vir my, grootse dekade van Franse filosofie (1968-1980+) het Michel Serres (wat meesal ongenoemd bly) ingesluit. Terwyl daar meesal na sy tydgenote verwys word as die poststrukturaliste is daar selfs na hom verwys as die enigste werklik strukturele (of selfs strukturalistiese) denker, veral geïnspireer deur sy studie van die wiskunde. Sy heel merkwaardige Hermesreeks van vyf volumes wat van hom die enigste filosoof van inligting en kommunikasie, waarvan ek kennis dra, gemaak het, het gedurende hierdie tyd die lig gesien.

Verskeie ontmoetinge met hom, by sy huis, by die Franse Akademie, in koffiekroegies in Parys, in die nuwe Franse Nasionale biblioteek, en selfs in 'n plaaslike wildreservaat, die lees van sy boeke en daarmee ook die belewing van die rykdom en inspirasie van sy boeiende en uitdagende insigte en gedagtes maak die lewe op blywende wyse onnoembaar ryk en vol, selfs in hierdie tyd wat gevul word met ' $n$ enkele allesoorheersende retoriek oor ' $n$ pandemie. So het sy lewe deel van myne geword. Sy omvangryke nalatenskap en ook vriendskap, 'n soort kosbare erflating, is onkoopbare rykdom - onvernietigbaar.

Sou 'n huldeblyk aan so iemand in die troosteloos onfilosofiese Suid-Afrikaanse omgewing hoegenaamd sin maak, of indruk maak, of bloot 'n vermorsing van woorde wees? Ons moet onthou: allerlei slimmighede is nog nie, en nie noodwendig intelligensie nie, en nog minder weelderige, volwaardige denke. Sy speelse, spelende, vrolike denke neem 'n mens in opwindende nuwe wêrelde in waarvan jy jou die bestaan nie kan voorstel of verbeel nie. Die ondeundheid wat blywend tot die einde in sy oë gevonkel het, vind op 'n besondere wyse uitdrukking en weerklank in sy denke en dus in sy werke. Dit is nooit swaarmoedig nie, selfs in die swaarmoedigste omstandighede, al is al sy werk volgens hom te verbind aan en aangespoor deur die weersinwekkende verskynsel van geweld. Hirosjima, het hy meermale gesê en geskrywe, het hom tot die filosofiese gedwing. En dit het hy aangevul met sy, vir baie onverstaanbare, parallel tussen die ontploffing van die ruimtetuig "Challenger" waarin sewe mense gesterf het (wat vir hom neerkom op wetenskaplike misdadigheid) met die standbeeld van die afgod Baäl waarin mense gereeld vir die afgod geoffer is. Nogtans kon hy nog kort voor sy dood in 'n radiopraatjie soos volg uitspel hoe sentraal geluk eintlik in ons lewens hoort te wees: vreugde is alledaags volgens hom. Dink maar net aan moeders wat hul kinders koester, kinders wat speel, die lewende liggaam wat fisies aktief is, vriende wat lief is en omhels, die invensies van nuwe idees, die toegewydes aan hulle werk, die oues van dae wat hulle verlustig 
in die lengte van hul dae - kyk net na die produseerders van vreugde wat oneindig meer talryk is as die ellendes waarvan mense prooi kan wees. Ongeluk (moord, korrupsie, katastrofes, die kwaad, ensovoorts), wat gewoonlik die voorblaaie en hoofberigte haal, is en bly meesal uitsonderlik hierteenoor.

Om hierdie denker te kon leer ken was om 'n ander lewe binne te gaan. Sy verset teen dogmatismes (Statues) soos die kritisisme, is geheel en al bevrydend al verloor dit nooit in die minste respek vir die diepgaande, die fundamentele en die etosmatige nie. Sy liefde vir die lewe en die dinge (Biogea) word nooit gestuit of gerem deur die onstuimigheid en vernietigende stormagtigheid van geweld nie.

Om sy wegwees te betreur sou nie sy wens wees nie, want die lewe wat nog vir die treurendes gegun word, is te vreugdevol om te rou. Om sy menswees en denkvernuf te huldig en te eer sou aan hom vreugde verskaf. Die dood is altyd seer, maar sy nalatenskap is so groot, ryk en vol en die herinneringe daaraan en die verfrissende en gereelde weer-kyk daarna so besonder kosbaar dat om juis daar te verwyl gedagtig aan hom en sy werk 'n geestelike rykdom bied wat nie uitgeput en opgebruik kan word nie. Dit bly altyd vars, nuut en invensievol.

Sy werke is weliswaar vir baie, en selfs vir diegene wat van beter behoort te weet, obskuur en moeilik toeganklik. Dit vra ontginning, uitleg, verwonderende leesentoesiasme en ontsyfering - die geheimenisse van vernuftige leeswerk. Hierdie soort leeshandelinge ontsluit asemrowende wêrelde, die weelde van die dinge, die onnoembaar verwonderenswaardige van die lewende in al die omvangryke rykdomme daarvan. Die toegang wat hierdeur verleen word tot geestesvolheid kan nouliks oorwaardeer word en noukeurig na waarde geskat word. Sy ontsluiting van die skatkamers van die werklikheid laat 'n mens telkens na jou asem snak. Om hierdie insigte te mis kan slegs bydra tot die betreurenswaardige en mistroostige geestesarmoede van hedendaagse samelewings en individuele lewens wêreldwyd.

Sommige van die mees prominente sake wat hy in sy werke beklemtoon wat heel besondere sin maak wanneer ek aan hom dink, sluit die volgende in:

- Sy soort klem, uniek en eiesoortig, op die formidabele en opwindende van komposisionele denke

- Sy klem op die lewensnoodsaaklike van die gees van invensie en inventiwiteit

- Sy omhelsing van en liefde en pleidooie vir wysheid, letterlik vir die filosofiese

- Sy besondere klem op grensoorskrydende, meervoudige en interkonnektiewe kennis en die oormaat daarvan

- $\quad$ Sy letterlik pryswennende perspektiewe op menswees, mensbeeld en menswording en die unieke weelde van sintuiglike ervaringe en desondanks sy hewige protes teen die verheerliking van menseregte sonder inagneming en dikwels ten koste van die regte van natuurlike dinge (lewendig of dood) in terme van 'n natuurkontrak

- Sy vreugdevolle, onblusbare entoesiasme vir die lewe, die natuur en die dinge

- Sy klem op die skeppendheid, die poëtiese, van taal en die fatale domheid van te strewe na slegs een wêreldtaal (waarna vele klaarblyklik smag!)

- Sy hele lewe lank bly hy stomgeslaan deur die haat vir intelligensie wat onmiskenbaar deel vorm van die stilswyende sosiale kontrak van sogenaamde intellektuele establishments.

\section{KARAKTERS, KERNFIGURE, GESKEP VIR SY FILOSOFERING}

Die storie van hierdie entoesiastiese liefhebber van die lewe, 'n nuuskierige van die wêreld, die avonturier van die denke, dwing tot refleksie, diepgaande nadenke, besinning. Hy was 'n 
mens van die aarde, 'n rugbymens, filosoof, historikus van die wetenskappe, akademikus van formaat soos min. Hy reis deur wêrelde, wetes en kulture. Sy fassinerende, onklassifiseerbare werke neem die vorm aan van 'n pantopie (van die Grieks pan = alles en topos = plek). Hy het voor enigiemand die rewolusies van die wêreld gesien en voorsien: die koms van inligting en kommunikasie, die sorg vir die liggaam, die ekologiese krisisse, die digitale omwentelinge, en religieuse metamorfoses.

Om elk van hierdie gebeure te artikuleer het hy nuwe konsepte en karakters, kernfigure, geskep: Pantopie, Hermes, Thanatokrasie, Hominessent, die Ware kwaad, Natuurkontrak, Petit Poucette (vroulik), Hermafrodiet, Groot Narratief en Fetish, en hy verbeel hom dat dit wat hy karakters noem juis vorm aanneem in die nuwe ervaringe van menswees in ons tyd.

\section{ENKELE TEMATIESE SIERADE UIT SY DENKE WAT MEESAL HIERBY AANSLUIT}

- Hermes, die boodskapper van die gode, waaraan hy die eerste vyf (ses?) boeke in sy oeuvre gewy het as 'n indringende studie oor en bespreking van die inligting en kommunikasierevolusie waarvan die einde nog nie eers bereik is nie.

- Die thanatokratiese (die mag van die dood) van die wetenskap: die keuse in die wetenskapgeskiedenis vir Mars teenoor Venus. Volgens hom het hierdie keuse 'n dodelike impak op die wetenskapgeskiedenis wat sou volg.

- Epistemologie impliseer dat rasionaliteit slegs in die wetenskappe en nêrens anders nie bestaan. Dit is nóg rasionalisme nóg 'n geldige en getroue beskrywing van rasionaliteit, maar doodgewoon 'n kaping.

Want rede en uitnemendheid kan op baie ander gebiede as in kanonieke wetenskap gevind word. Omgekeerd kan 'n mens in laasgenoemde net soveel mites vind as in ouvroustories. Die heel beste hedendaagse mite is die idee van 'n wetenskap wat gesuiwer is van alle mites. Hoe meer 'n mens mite probeer uitsluit, hoe meer keer dit met krag terug.

- Die pragmatogoniese: die skeppende en vormende mag van die dinge oor subjekte eerder as die mag van subjekte oor dinge.

- Die noodsaaklikheid van 'n teorie van "wulpse” kennis

Ons behoort 'n teorie van obskure, verwarde, donker, nie-evidente kennis te inventeer - 'n teorie van "adelos"-kennis (afkomstig van die Griekse eiland Delos, wat vroeër A-delos (die verborge/versteekte eiland) genoem was). Hierdie lieflike byvoeglike naamwoord, met vroulike resonansies, beteken dat iets sigself versteek/verberg en nie sigself openbaar/wys nie.... Skaduwee vergesel lig, net soos teen-materie materie vergesel. (Teenoor die "wetenskapfilosoof" wat plegtig verklaar: in wetenskap gaan dit slegs oor feite en is daar geen plek vir bygeloof en vooroordele nie, waarteenoor 'n wetenskaplike skrywe: Die kuns is: bly maar skepties oor alle "feite") [lees saam met die tweede kolpunt hier bo].

- Die skrywer se roeping: Om vir 'n lang tyd sy sitplek reg binne in die woordeboek te maak: Hoe ryker sy taal hoe betroubaarder sy werk. Hy plaas veral die klem op die belangrikheid daarvan om nuwe woorde vir nuwe situasies te skep. En vir die aandag van die denker: om goed te dink, vereis talryke woorde. Ons moet versigtig wees om nie die onuitspreeklike met die gebrek aan woordeskat te verwar nie (teenoor die filosoof wat stel: dit is onnodig vir studente om woordeskat te bou).

- Invensie is die kernsaak waarna hy telkens terugkeer, vandaar sy Cartesiaanse nuanse: 
Ek inventeer, daarom is ek. Volgens hom is invensie die enigste outentieke intellektuele handeling.

- Die onblusbaarheid van taal in die poëtiese lewe

Die mag van die poëtiese lewe artikuleer hy so: Veel belangriker as middel tot kommunikasie is taal dit wat ons maak wat ons is. Dit maak van ons individue, mense. Die poësie beroep sig op hierdie funksie van taal. Dit laat ons onsself wees. Dit maak ons liggaam, ons gees, ons bewussyn, ons menswees, ons aard. Taal moet van geboorte af aanvaar word, want ons word in taal gebore. En dan verder, nog veel vroeër, beklemtoon hy:

Wanneer alle mense in die wêreld uiteindelik dieselfde taal praat en volgens dieselfde boodskap of volgens dieselfde norme van redelikheid kommunikeer, sal ons neerdaal, idiotiese imbesiele, laer as rotte, veel dommer as akkedisse. Dieselfde maniakale taal en wetenskap, dieselfde herhaling van name op alle vlakke - 'n aarde oordek met skreeuende parkiete. Die verwerping van 'n taal is die kenmerk van geveinsde naïwiteit of waaragtige domheid.

- Gevange filosowe beweeg nie, hul herhaal slegs

Wanneer filosofie verstrik raak en opgesluit word in akademia, beweeg dit nie veel nie. Wat wel wêreldwyd voortgaan is die instellinge waarvan die funksie die reproduksie van gehoorsame jongmense bly.

- Die opwindende aard van die liefde vir die lewe en die lewe tussen en met die dinge op ' $n$ ten volle intense wyse en in heelhartige bewustheid (Biogea).

- Meervoudige, konnektiewe intelleksie: die lewensbelangrike beweeglikheid tussen die dissiplines deur hoe moeilik dit ook al mag wees. (Saam met laaste kolpunt op p. 857 te lees).

- Hy het 'n heel merkwaardige wysgerige antropologie in nie minder nie as nege boeke ontwikkel. Hy het begin met "Die Parasiet" (1980) waarin hy ondersoek hoe menseverhoudings identies is aan dié van die parasiet tot die liggaam van die gasheer en wat ook gesien kan word as voorloper van 'n postmoderne mensbeskouing. Dit is gevolg deur 'n boeiende bespreking van menslike sintuiglikheid (Vyf Sintuie 1985) wat in die tyd van data en inligtingtegnologie afgeskeep word en waarvolgens sintuiglikheid oorheers word deur taal. Geen wonder dat mense minder belangstel in die smaak van wyn as in die beskrywing van die wyn op die bottel se etiket nie. Op hierdie wyse word 'n steriele kennisstelsel geskep wat geskei is van liggaamlike ervaringe. Dan volg sy boek oor die menslike liggaam (1999) wat hierby aansluit en waarin hy beklemtoon dat die menslike liggaam met gemak die dinge en die lewende naboots; dit skep selfs tekens. Uit die velerlei variasies van posisies en metamorfoses van die liggaam word die gees gebore. Die liggaam is veel moeiliker om te "robotiseer" as die intelligensie met verwysing na kunsmatige intelligensie. Die vyf sintuie is nie die enigste bron van kennis nie; kennis spruit grootliks voort uit die nabootsinge wat moontlik gemaak word deur die buitengewone plastisiteit van die liggaam as geheel. Hierin, hierdeur en hiermee kom kennis voort. Hierna het hy vier volumes oor mensbeeld geskep wat hy as sy eintlike antropologie beskou en waarvan die eerste twee titels Hominessent (2001) en Inkandessent (2003) die merkwaardigste is. Hy sluit sy reeks oor menswees af met Petite Poucette (die vroulike vorm) (waarvan meer as 'n kwartmiljoen eksemplare in Frans al verkoop is) wat 'n nuwe ruimte skep wat vra vir oop, inventiewe denke wat klop met die transformasie van ons liggame, ons tegnologieë en ons kennisvorme en sosiale organisasies. Hy gebruik hiervoor die beeld van die skooldogter wat hy in die Metro in Parys dophou wat met haar twee 
duimpies teksboodskappe per selfoon na vriende stuur en dan gebruik hy hierdie beeld om iets veel breër oor menswees te illustreer: dat mense gevorm word deur hulle tegnologie en dat met die koms van rekenaars, selfone, en die internet 'n nuwe soort mens gebore is. Hierdie nuwe mens, of menswording, word op 'n besondere wyse uitgebeeld en beskrywe in die twee genoemde boeke Hominessent en Inkandessent wat taalkundig klop met adolessent (volwassewording). Al hierdie terme dui op 'n staat of ' $n$ handeling wat in die proses is om sigself te vorm, of, om 'n metamorfose te ondergaan. Hy het, om dit kortweg te stel, oor hierdie twee temas die volgende in 'n latere onderhoud te sê gehad: Die hominessent het die krag verkry om te verander, om metamorfose te bewerkstellig, te ondergaan en om te transformeer - menswording is aan die gang en word nooit afgehandel nie. Die hominessent is 'n menslike faset van 'n veel groter fenomeen wat hy inkandessent noem (letterlik die gloeiende of hittegewende). Die mens is toegerus met die kapasiteit om te metamorfoseer. Wat die mens kan word is onvoorsienbaar en onvoorspelbaar. Die mens is die wese met moontlikhede: hy is in staat tot allerlei fisiese aktiwiteite, maar veral ook in staat om te inventeer. Die Inkandessent het veral die kapasiteit om te inventeer. Meer nog: die inkandessent is die inkarnasie van alle menslike kapasiteite; dit het die krag daartoe en die gloeiende vurigheid vir die verwesenliking daarvan - vir herkapasitering. Hierdie persoon is in staat tot .... komposisionele denke, tot die skep van wêrelde, van nuwe individue, van gemeenskappe, van etos, van kennisvorme en wetes, van die oorwinning oor parasitismes en narcissisme, en veral ook van die invensie van 'n sinvolle en leefbare toekoms.

- Brûe en verhoudinge: die filosofie van brugbou, om tussenmenslike verhoudinge te illustreer en te bewerkstellig, moontlik te maak, word pragtig geïllustreer in 'n spesiale bundel L'art des Ponts. (Die kuns van brûe).

- Pantopiaan: hy bewandel alle weë ten einde behoorlik te kan filosofeer.

Hy stel dit so: Uit 'n oorsig oor die titels van my boeke sal jy met groot gemak kan naspoor hoe ek van wiskunde na fisika, van fisika na die lewenswetenskappe, en van die lewenswetenskappe na die menswetenskappe oorbeweeg het, sonder om ooit hulle historiese komponent agterweë te laat. Maar dit skep nie 'n naatlose lys of 'n kategorie wat 'n homogene oppervlakte beset nie; hulle suggereer inteendeel 'n tormente, ondulêre landskap - chaoties, fraktaal, maar getrou aan die werklikheid (kyk ook die 4de kolpunt) .

- Die onderrigte derde is die troebadoer van kennis wat die intensiewe en volhoubare artikulasie tussen die wetenskappe van die natuur, die wetenskappe van die gees en die filosofiese fasiliteer en bevorder. Die vertaler artikuleer hierdie stelling soos volg:

"The Troubadour of Knowlegde [as title for the book Le tiers-instruit] was chosen to reflect Michel Serres's identification of the third-instructed with the troubadour, his equation of learning and knowing with finding and inventing. Throughout the text, knowledge, learning, and philosophy are linked to travel, to seeking and encountering, to intersection of genres and disciplines, and to the felicitous use of language."

\section{AFSLUITING}

In 'n betreklik onlangse reeks onderhoude oor sy lewenswerk wat ook 'n besondere soort weergawe van sy lewe is, sluit hy in antwoord op die laaste stelling en vraag soos volg af: 
Die stelling: Om op te som, die lewe is slegs die pyn om geleef te word werd indien daar liefde is en indien daar denke is, waarop hy antwoord:

Waarna strewe ek om elke dag te doen? 'n Mooi bladsy, aan die een kant, en 'n lewe gedra deur liefde aan die ander kant.

Die vraag: Watter gevoel, om mee af te sluit, trek jy saam uit alles waaroor gepraat is, jou lewe en werk?

Sy antwoord: Vreugde! Die eenvoudige kontingente vreugde van te bestaan; die vreugde van die geweld van verskeie oorloë te kon oorlewe; die vreugde, hier en nou, van vrede wat al vir meer as 'n halfeeu duur; die vreugde verskaf deur die skoonheid van die wêreld en die van vroue; die drievoudige vreugde om lief te hê, wonderbaarlik drievoudig omdat dit jou, my, en ons verhouding verbind; die vreugde van te onderrig, te luister, te skrywe, en te praat, om te maak en te fabriseer (te inventeer); die uitgelate vreugde van die liggaam, van liefkosinge, van sport in al die vorme daarvan, en van musiek, die oormatige vreugde van denke in die oortreffende trap.

Wie sou hulle nie heelhartig met hierdie gelade gevoelens kon of wou vereenselwig nie? Mag hierdie oorsig tot groot vreugde dien vir wie ook al wil deel in so 'n vreugdevolle filosofiese lewe.

Hierdie is 'n brute oorsig oor wat ons van Michel Serres kan en eintlik moet leer en waaroor ons deeglik en deurlopend behoort te reflekteer, behoort te besin, ter wille van ons eie geestelike welstand.

\section{EIE BYDRAES OOR SY WERK}

1 Hermes overtaken (RSA 2000, RGN) (1987).

2 Atlas of knowledges: in pursuit of new knowledge (Mousaion, XIX(1):35-52) (2001).

3 Pragmatogony: the impact of things on humans (Phronimon, 11(2):5-17)(2007).

4 The challenge to the contemporary knowledge worker: the troubadour of knowledge, Managing knowledge workers: a new HR paradigm, onder redaksie van Sukvinder Kaur Multani. Hyderabad: The Ictai University Press (2007).

5 Troubadour of knowledge: a knowledge worker for the new knowledge age, in Paradigms and conceptual systems in knowledge organization, edited by C. Gnoli and F. Mazzocchi. (2010). Würzburg: Ergon Verlag. (Hierdie hoofstuk is 'n verwerking vir hierdie uitgawe van die publikasie onder kolpunt 4 genoem).

Hierdie hoofstuk is ook in Pools vertaal en gepubliseer in Bibliotekarz Podlaski, nr. 22 (2011).

6 Michel Serres' multidisciplinary philosophy of information and knowledge. The Journal for Transdisciplinary research in Southern Africa, 10(1):19-36) (2014).

7 Multiple, connective intellection. The Journal for Transdisciplinary Research in Southern Africa, 11 (2) (2015).

\section{CS (FAnie) de BeER}

Emeritus professor

Universiteit van Suid-Afrika

E-pos: Careldebeer17@gmail.com 